\title{
Computed Tomography Scan Findings among Pediatric Patients with Unprovoked Seizures: a Hospital-Based Study
}

\author{
Anna Karina Joson-Sanglay ${ }^{1}$ and Rogelio I. De Jesus ${ }^{2,3,4}$ \\ ${ }^{1}$ Department of Radiology, Philippine General Hospital, University of the Philippines Manila \\ ${ }^{2}$ Department of Radiology, College of Medicine and Philippine General Hospital, University of the Philippines Manila \\ ${ }^{3}$ Occidental Mindoro Provincial Hospital, Mamburao, Occidental Mindoro \\ ${ }^{4}$ Medical Center Parañaque, Sucat, Parañaque City
}

\begin{abstract}
Objective. To describe the radiologic findings in pediatric patients who underwent cranial CT scan for unprovoked seizures at the Philippine General Hospital (PGH) and determine whether there is any association between the demographic characteristics such as age, age at onset, gender, as well as normal or abnormal neurologic examination findings, and the abnormal CT scan findings.

Methods. Official results of all pediatric patients who underwent cranial CT scan for unprovoked seizures from January 1, 2015 to December 31, 2015 in PGH were reviewed. Data were described and statistically analyzed for differences in CT scan findings between different sexes, age groups, ages at onset, and presence or absence of neurologic findings.

Results and Conclusion. Of the 88 cases included, 29 (32.95\%) had abnormal CT findings. The most common finding was volume loss. No statistically significant difference was noted for the frequency of abnormal CT findings between categories. There was a trend towards more frequent abnormal CT scan findings among males, and among patients exhibiting abnormal neurologic findings.
\end{abstract}

Key Words: unprovoked seizure, cranial CT scan, pediatric seizure

\section{INTRODUCTION}

Seizure is a common cause for pediatric consults at the emergency department because it is a disturbing event to the family of the child. ${ }^{1}$ Majority of pediatric patients who undergo a CT scan examination for seizures have unremarkable findings. ${ }^{2-5}$ When abnormal, common CT scan findings are cerebral atrophy, brain infarct, encephalomalacia, and cerebral dysgenesis. ${ }^{3,46}$ Most abnormalities noted do not have clinical implications. ${ }^{6}$

The practice parameter published by the American Academy of Neurology in 2003 recommends MRI evaluation if an imaging study is to be done, due to its higher sensitivity and specificity. ${ }^{6,12} \mathrm{CT}$ scan evaluation may still be acceptable as an alternative procedure in cases where an MRI cannot be performed. CT scan can identify large structural abnormalities. Subtle lesions may be missed. ${ }^{7,810}$ Eliminating

Corresponding author: Anna Karina Joson-Sanglay, MD Department of Radiology Philippine General Hospital

University of the Philippines Manila

Taft Avenue, Ermita, Manila 1000 Philippines

Telephone: +639436608198

Email: annajsanglay@gmail.com unnecessary imaging and using dose-reducing strategies, especially for pediatric patients, can reduce future radiationinduced cancers. ${ }^{9}$

In the Philippine General Hospital (PGH) setting, compared to MRI, a cranial CT scan is still the more commonly requested imaging study for the evaluation of 
a patient presenting with seizure. A CT scan study has a shorter scanning time and costs less than an MRI study. The shorter scanning time translates to more scanned patients in a day and less need for sedation among younger children who cannot keep still.

It is important to evaluate how much information CT scan studies give and if these aid in the prognosis and management of the patient. It is also useful to note if there are certain patient characteristics that make a CT scan study more useful. The end goal is to decrease the unnecessary use of CT scan evaluation.

\section{OBJECTIVES}

This study aimed to describe the frequency of abnormal radiologic findings in $\mathrm{PGH}$ pediatric patients who underwent cranial CT scan for unprovoked seizures in 2015. It aimed to determine the number of normal versus abnormal findings in CT scan. It also aimed to determine whether there is any association between the demographic characteristics such as age, age at onset, gender, as well as normal or abnormal neurologic examination findings, and the abnormal CT scan findings.

\section{METHODS}

\section{Study design}

This was a retrospective descriptive study based on a review of PGH Radiology Department records of all pediatric patients who underwent cranial CT scan for unprovoked seizures from January 1, 2015 to December 31, 2015.

\section{Inclusion and exclusion criteria}

Records of pediatric patients who underwent cranial CT scan examination for unprovoked seizures from January 1, 2015 to December 31, 2015, in the PGH Radiology Department were included in the study. Records that were included contain the request form with chief complaint, history and neurologic physical examination, and a signed CT scan consent form. Records of patients who experienced at least one episode of unprovoked seizure, including those with epilepsy were included. Records of patients who underwent plain and/or contrast-enhanced cranial CT scan were included. Cases with incomplete physical records or no PGH CT scan number were excluded from the study. Patients with provoked seizures (associated with trauma, fever, infection, metabolic imbalance, medication, chronic disease, etc ${ }^{11}$ ) or acute symptomatic seizures, who underwent a non-cranial CT scan, or who had CT scan examinations done outside PGH were excluded as well.

\section{Data acquisition}

Cases were identified by searching electronic records of all pediatric CT scan results at the Radiology Department for a history of "seizure", "epilepsy" or "convulsion". Initial screening was done to exclude search results that met any of the exclusion criteria. Patients with unclear indication based on the short history in the electronic records were included for later review. For the remaining patient result records that were not excluded, each patient's name, age and CT scan case number were listed and encoded in the Case Identification Form. For anonymity, patient name and CT scan number were not printed. For purposes of this study, a unique case number was assigned to each identified case.

All retrieved records were reviewed by the researcher for adequacy of notes on chief complaint, history, pertinent neurologic examination, demographic data, and consent form.

Pertinent data from the remaining physical records were encoded in the Data Collection Form, including any abnormal neurologic examination. The investigator then retrieved the electronic copies of the official results for the remaining records. The abnormal CT scan findings were encoded in the Data Collection Form.

\section{Data tabulation and statistical analysis}

Population characteristics and demographics were described (Table 1). Abnormal CT scan findings were counted and abnormalities were listed. Quantitative data were tabulated and analyzed using the Chi-square test to see if there was any statistically significant difference in the number of abnormal versus normal CT scan findings between different patient characteristics (age, age at onset and sex), and presence of abnormality in the neurologic examination (Tables 2, 3, 4 and 5).

Table 1. Demographic information of the pediatric patients who underwent CT scan examination for unprovoked seizures in PGH in 2015

\begin{tabular}{cc} 
Characteristic & $\begin{array}{c}\text { Number of patients } \\
\text { (Percentage in the population) }\end{array}$ \\
Age & $6.5 \pm 5.37$ \\
\hline Less than 1 & $19(21.6 \%)$ \\
1 to $<6$ & $22(25 \%)$ \\
6 to $<12$ & $29(33 \%)$ \\
12 to 18 & $18(20.5 \%)$ \\
\hline Sex & \\
\hline Female & $34(38.6 \%)$ \\
Male & $54(61.4 \%)$ \\
\hline Age at onset & $5.2 \pm 5.19$ \\
\hline Less than 3 & $38(43.2 \%)$ \\
3 to $<12$ & $36(40.9 \%)$ \\
Above 12 & $12(13.6 \%)$ \\
Missing & $2(2.3 \%)$ \\
\hline Neurologic findings & $62(93.2 \%)$ \\
\hline Abnormal &
\end{tabular}

\section{Ethical consideration}

The protocol was submitted to the University of the Philippines Manila Research Ethics Board (UPMREB) Panel for ethics review and approval. The study was conducted only upon approval of the protocol by the UPMREB Panel. All patient information was anonymized and kept confidential. 
Table 2. Chi-square test of correlation between sex and abnormal CT scan result in pediatric patients who underwent cranial CT scan for unprovoked seizures in PGH in 2015

\begin{tabular}{cccc} 
Sex & $\begin{array}{c}\text { Number of negative CT scan findings } \\
\text { (Percentage in subgroup) }\end{array}$ & $\begin{array}{c}\text { Number of abnormal CT scan findings } \\
\text { (Percentage in subgroup) }\end{array}$ & p-value \\
Female & $26(76.5 \%)$ & $8(23.5 \%)$ & 0.2073 \\
Male & $33(61.1 \%)$ & $21(38.9 \%)$ & \\
\hline
\end{tabular}

Table 3. Chi-square test of correlation between age during the scan and abnormal CT scan result in pediatric patients who underwent cranial CT scan for unprovoked seizures in PGH in 2015

\begin{tabular}{cccc}
\hline Age & $\begin{array}{c}\text { Number of negative CT scan findings } \\
\text { (Percentage in subgroup) }\end{array}$ & $\begin{array}{c}\text { Number of abnormal CT scan findings } \\
\text { (Percentage in subgroup) }\end{array}$ & $\begin{array}{c}\text { p-value } \\
\text { Less than } 1\end{array}$ \\
1 to $<6$ & $12(57.1 \%)$ & $7(32.9 \%)$ & 0.8625 \\
6 to $<12$ & $13(65.0 \%)$ & $6(23.3 \%)$ \\
12 to $<18$ & $23(26.7 \%)$ & $6(35.3 \%)$ \\
\hline
\end{tabular}

Table 4. Chi-square test of correlation between age at onset and abnormal CT scan result in pediatric patients who underwent cranial CT scan for unprovoked seizures in PGH in 2015

\begin{tabular}{cccc} 
Age at onset & $\begin{array}{c}\text { Number of negative CT scan findings } \\
\text { (Percentage in subgroup) }\end{array}$ & $\begin{array}{c}\text { Number of abnormal CT scan findings } \\
\text { (Percentage in subgroup) }\end{array}$ & p-value \\
Less than 3 & $23(60.5 \%)$ & $15(39.5 \%)$ \\
3 to $<12$ & $28(77.8 \%)$ & $8(22.2 \%)$ \\
Above 12 & $6(50 \%)$ & $6(50 \%)$ \\
Missing & $1(100 \%)$ & \\
\hline
\end{tabular}

Table 5. Chi-square test of correlation between neurologic findings and abnormal CT scan result in pediatric patients who underwent cranial CT scan for unprovoked seizures in PGH in 2015

\begin{tabular}{cccc} 
Neurologic findings & $\begin{array}{c}\text { Number of negative CT scan findings } \\
\text { (Percentage in subgroup) }\end{array}$ & $\begin{array}{c}\text { Number of abnormal CT scan findings } \\
\text { (Percentage in subgroup) }\end{array}$ & p-value \\
No abnormal neurologic findings & $23(60.5 \%)$ & $15(39.5 \%)$ & 0.1598 \\
With abnormal neurologic findings & $57(69.5 \%)$ & $25(30.5 \%)$ & 0.1703 \\
\hline
\end{tabular}

\section{RESULTS}

The study included records of 88 pediatric patients with an average age of 6.5 years. The sample population was welldistributed across age groups, with $21.6 \%$ of the patients less than a year old, $25 \%$ from 1 to less than 6 years old, 33\% from 6 to 12 years old, and $18 \%$ in the 12 to 18 age group. It consisted mostly of males (61.4\%). The average age at onset of seizures was $5.2 \pm 5.19$ years. Thirty-eight $(43.2 \%)$ of the patients experienced their first seizure before they were 3 years old, while $36(40.9 \%)$ had their first seizure between 3 and less than 12 years of age. Two records did not state the age at onset. Majority $(82,93.2 \%)$ of the patients presented with normal neurologic finding at the time that they were examined by the requesting physician. Only 6 (6.8\%) patient records contained abnormal neurologic findings (Table 1).

Abnormal CT scan findings were present in 21 males (38.9\% of the male population) and 8 females $(23.5 \%$ of the female population). Using the chi-square test, a p-value of 0.21 was calculated (Table 2 ).

The frequency of abnormal CT scan findings among the four age groups (less than 1 year, 1 year to less than 6 years, 6 years to less than 12 years, and 12 years to less than 18 years) were 9, 7, 6 and 7 (or 47.4\%, 31.8\%, 20.7\%, and 38.9\%) of each age group, respectively. The $p$-value calculated was 0.86 using the chi-square test (Table 3).
The groupings for age of first seizure were a) less than 3 years old, b) 3 to less than 12 years old, and c) 12 years old and above. Abnormal CT scan findings were seen in $15(39.5 \%), 8(22.2 \%)$, and $6(50 \%)$ patients within the abovementioned groupings, respectively. Using the Chisquare test, the p-value calculated was 0.16 (Table 4).

Eighty-two (93.2\%) of the included 88 patients had negative neurologic findings recorded during their consult with the physician requesting the CT scan. Six (6.8\%) had abnormal neurologic findings. Twenty-five (30.5\% of 82 ) of those who had normal neurologic exams had abnormal radiologic findings, while 4 (66.7\% of 6$)$ of those who had abnormal neurologic exams had abnormal CT scan findings. Using the Chi-square test, a p-value of 0.17 was calculated (Table 5).

No statistically significant association was found between abnormal or negative $\mathrm{CT}$ scan findings and the patient's age, sex, age at onset, or neurologic examination findings (Tables 2 to 5).

Some of the official CT scan results had more than one abnormal finding. Because of this, there were 40 findings in 29 abnormal CT scans. Volume loss was the most common finding, seen in 13 (45\%) of the CT scan-abnormal patients. Hydrocephalus and temporal lobe abnormality were less common at 5 (17\%) each, while microcephaly and mass/new growth both had an incidence of 4 (14\%) among the patients. 


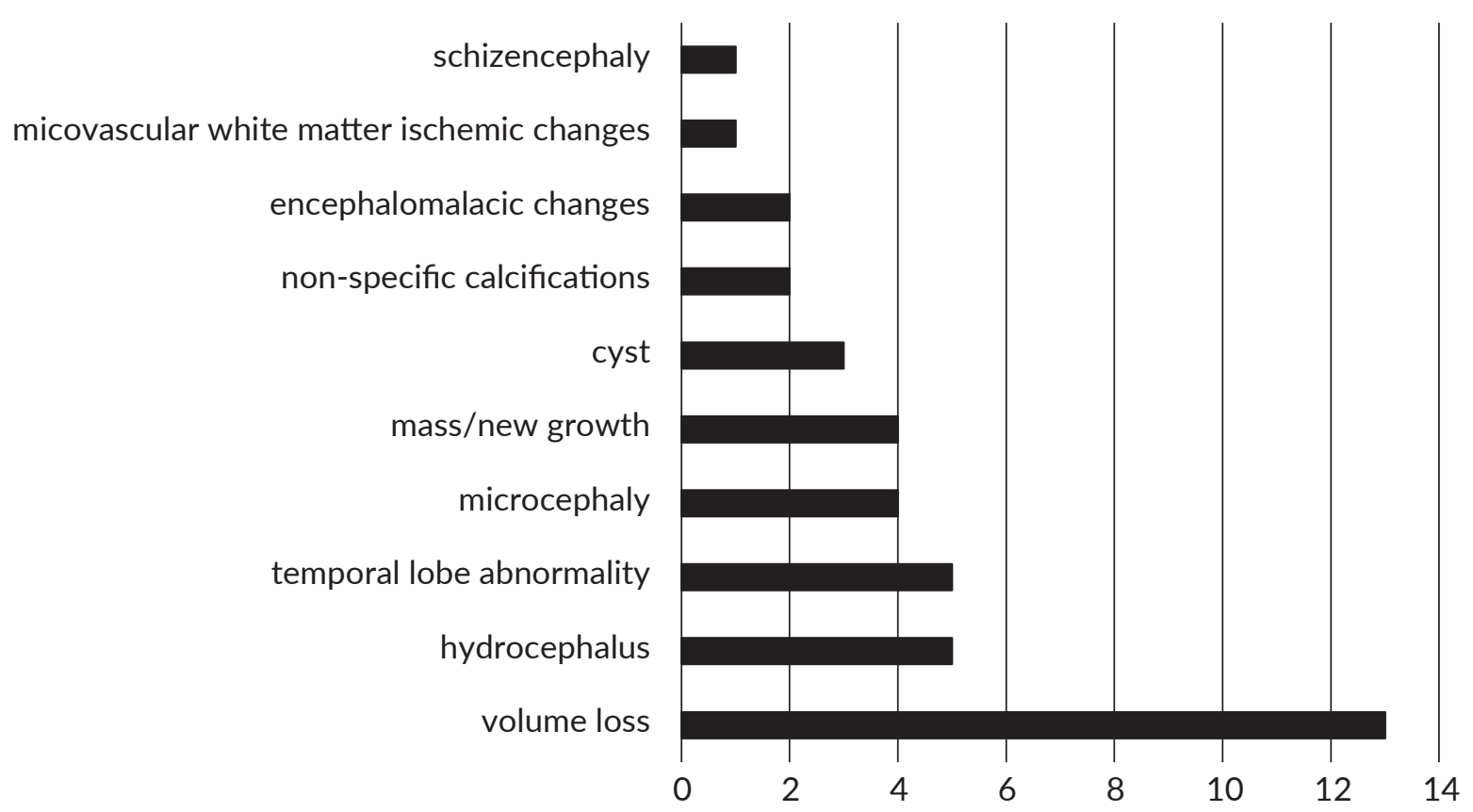

Figure 1. Frequency of findings in the $29 \mathrm{CT}$-abnormal pediatric patients who underwent a CT scan for unprovoked seizures in PGH in 2015.

Other findings were cysts, non-specific calcifications, encephalomalacic changes, microvascular white matter ischemic changes, and schizencephaly (Figure 1).

\section{DISCUSSION}

Pediatric patients who underwent a cranial CT scan in the Philippine General Hospital in 2015 for unprovoked seizures were mostly male (61\%), had an age at onset prior to 12 years old ( $43 \%$ at less than 3 years old and $41 \%$ at 3 to less than 12 years old), and had no neurologic findings during their consult with the requesting physician (93.2\%). The larger percentage of males versus females, with a ratio of approximately 3:2, was reflective of the epidemiologic review by Martindale et al which showed a predominance of males presenting in the emergency department with seizures across all age groups. ${ }^{13}$ The predominant age at onset was less than 12 years old despite the population being fairly distributed across age groups.

There was a larger proportion of normal CT scan findings compared to abnormal findings (67.05\% unremarkable/ normal versus $32.95 \%$ abnormal). This agreed with existing data such as in the study of Maytalet $\mathrm{al}^{14}$ and Highighi et $\mathrm{al}^{2}$ where they found that the majority of pediatric seizures show normal CT scan findings. This indicates a need for better screening of patients presenting with unprovoked seizure to decrease the number of patients who are unnecessarily exposed to radiation and to decrease the expenditure for the examination.

No single demographic characteristic or neurologic finding was found to have statistically significant correlation with abnormal CT scan results. Several trends were noted. There was a higher number of abnormal CT findings in patients with the following: a) male gender, b) age at onset younger than 3 years old or older than 12, and c) abnormal neurologic findings during the consult with the requesting physician. More male patients had abnormal CT scan results, agreeing with previous studies. ${ }^{2}$ Patients with age at onset from 3 to less than 12 years old are less likely to have an abnormal CT scan finding. This partially agrees with the study done in Cameroon showing that majority of patients with an abnormal CT scan are less than 1 year old. ${ }^{3}$

Those with abnormal neurologic findings during their consult with the requesting physician were much more likely to have abnormal CT findings compared to those who presented at the clinic with an unremarkable neurologic examination. This agrees with previous studies. ${ }^{15,16}$ This shows the importance of CT scan study for patients with abnormal neurologic findings and emphasizes the need for the communication of good neurologic examinations from clinician to radiologist. The radiologist should be more vigilant in interpreting a cranial CT scan when there are neurologic abnormalities on physical examination.

The most common finding in an abnormal CT scan in this study was volume loss. This was also the most common finding in a similar study by Poudel. ${ }^{8}$ This observation may lead the clinician to investigate possible causes of the atrophy, which may be syndromic. In this case it may help in diagnosis and prognostication. The same was true for hydrocephalus and temporal lobe atrophy (17\% each), as well as for micro/macrocephaly (14\%). The most commonly found abnormalities were those that do not warrant intervention. 


\section{CONCLUSION}

Majority (67.0\%) of pediatric patients who underwent cranial CT scan in PGH for unprovoked seizures in $2015 \mathrm{had}$ normal CT scan findings. Among patients with abnormal CT findings, the most common finding was volume loss, followed by hydrocephalus and temporal lobe abnormality. There was no significant association between the presence of abnormal CT scan findings and the patient's age, sex, age at onset, or neurologic examination findings. There was a trend towards less likelihood of abnormal CT scan findings in patients with no neurologic abnormality, were female and/or had age at onset in the $>3-12$-year age range.

\section{RECOMMENDATIONS}

Future research may use data gathered here as a pilot study for reference. Further studies with a larger population are recommended to pursue the abovementioned trends. Additional research in the local setting may extend the population to include a larger sample base and /or longer period of study that may help in arriving at statistically significant findings.

Recommendations of this research for clinical practice are limited due to the lack of statistical significance of the review of records. However, it emphasizes the importance of a meticulous neurologic physical examination and communication of findings to radiologists by clinicians. Radiologists receiving requests with an abnormal neurologic finding should be extra vigilant for abnormal CT scan findings.

Requests for cranial CT scans for patients with unprovoked seizures should also be made judiciously to avoid unnecessary radiation exposure and expenditure. There is a need for the development of better criteria and screening to trim the pediatric population being sent for cranial CT scan in PGH for unprovoked seizures.

\section{Statement of Authorship}

All authors have approved the final version submitted.

\section{Author Disclosure}

All the authors declared no conflict of interest.

\section{Funding Source}

This paper was partially funded by the Philippine General Hospital and the authors.

\section{REFERENCES}

1. Hirtz D, Ashwal S, Berg A, et al. Practice parameter: evaluating a first nonfebrile seizure in children: report of the Quality Standards Subcommittee of the American Academy of Neurology, the Child Neurology Society, and the American Epilepsy Society. Neurology. 2000; 55(5):616-23.

2. Haghighi M, Baghery MH, Rashidi F, Khairandish Z, Sayadi M. Abnormal findings in brain CT scans among children. J Compr Ped. 2014; 5(2):e13761.

3. Moifo B, Nguefack S, Tapouh JRM, Mah E, Mbonda E, Fotsin JG. Predictive factors for abnormal brain CT-scan in childhood epilepsy at Yaoundé (Cameroon). Open Journal of Medical Imaging. 2014; 4(1):31-37.

4. Shinnar S, O'Dell C, Mitnick R, Berq AT, Moshe SL. Neuroimaging abnormalities in children with an apparent first unprovoked seizure. Epilepsy Res. 2001; 43(3):261-9.

5. Strobel AM, Gill VS, Witting MD, Teshome G. Emergent diagnostic testing for pediatric nonfebrile seizures. Am J Emerg Med. 2015; 33(9):1261-4.

6. Hirtz D, Berg A, Bettis D, et al. Practice parameter: treatment of the child with a first unprovoked seizure: Report of the Quality Standards Subcommittee of the American Academy of Neurology and the Practice Committee of the Child Neurology Society. Neurology. 2003; 60(2):166-75.

7. Recommendations for neuroimaging of patients with epilepsy. Commission on Neuroimaging of the International League Against Epilepsy. Epilepsia. 1997; 38(11):1255-6.

8. Poudel P, Chitlangia M, Gupta M. Computerized axial tomography findings in children with afebrile seizures: a hospital based study at eastern Nepal. Dev Med Child Neurol. 2015; 57(S5):104.

9. Miglioretti DL, Johnson E, Williams A, et al. Pediatric computed tomography and the associated radiation exposure and estimated cancer risk. JAMA Pediatr. 2013; 167(8):700-7.

10. Ghofrani M. Approach to the first unprovoked seizure- Part I. Iran J Child Neurol. 2013; 7(3):1-5

11. Hauser WA, Beghi E. First seizure definitions and worldwide incidence and mortality. Epilepsia. 2008; 49 Suppl 1:8-12.

12. Fisher RS, Acevedo C, Arzimanoglou A, et al. ILAE official report: a practical clinical definition of epilepsy. Epilepsia. 2014; 55(4):475-82.

13. Martindale JL, Goldstein JN, Pallin DJ. Emergency department seizure epidemiology. Emerg Med Clin North Am. 2011; 29(1):15-27.

14. Maytal J, Krauss JM, Novak G, Nagelberg J, Patel M. The role of brain computed tomography in evaluating children with new onset of seizures in the emergency department. Epilepsia. 2000; 41(8):950-4.

15. Khodapanahandeh F, Hadizadeh H. Neuroimaging in children with first afebrile seizures: to order or not to order? Arch Iran Med. 2006; 9(2):156-8.

16. Gaillard WD, Chiron $\mathrm{C}$, Cross $\mathrm{JH}$, et al. Guidelines for imaging infants and children with recent-onset epilepsy. Epilepsia.2009; 50(9):2147-53. 